\title{
Conserved zinc fingers mediate multiple functions of ZFP100, a U7snRNP associated protein
}

\author{
ERIC J. WAGNER, ${ }^{1,2}$ JASON K. OSPINA, ${ }^{3}$ YUE HU, ${ }^{1}$ MIROSLAV DUNDR, ${ }^{4}$ A. GREGORY MATERA, ${ }^{3}$ \\ and WILLIAM F. MARZLUFF ${ }^{1,2}$ \\ ${ }^{1}$ Department of Biochemistry and Biophysics, University of North Carolina at Chapel Hill, Chapel Hill, North Carolina 27599, USA \\ ${ }^{2}$ Program in Molecular Biology and Biotechnology, University of North Carolina at Chapel Hill, Chapel Hill, North Carolina 27599, USA \\ ${ }^{3}$ Department of Genetics, Case Western Reserve University, Cleveland, Ohio 44105-4955, USA \\ ${ }^{4}$ Department of Cell Biology and Anatomy, Rosalind Franklin University of Medicine and Science, Chicago, Illinois 60064, USA
}

\begin{abstract}
Formation of the $3^{\prime}$ end of replication-dependent histone mRNAs is most robust during $S$ phase and is mediated by both the stem-loop binding protein (SLBP) and the U7 snRNP. We previously identified a 100-kDa zinc finger protein (ZFP100) as a component of U7 snRNP that interacts with the SLBP/pre-mRNA complex. Here, we show that myc- or GFP-tagged ZFP100 overexpressed after transfection is concentrated in Cajal bodies (CBs), and unlike components of the spliceosomal snRNPs, photobleaching experiments demonstrate that ZFP100 is stably associated with CBs. Of the 18 zinc fingers contained within ZFP100, the region encompassing fingers 2-6 is sufficient to maintain CB localization. Zn fingers 5-10 are required for maximal binding of ZFP100 to a 20-amino-acid region of Lsm11, a U7 snRNP core protein. Expression of ZFP100 stimulates histone mRNA processing in vivo, assayed by activation of a reporter gene that encodes a GFP mRNA ending in a histone $3^{\prime}$ end. Importantly, the domain that is required for CB localization and Lsm11 binding is also sufficient to stimulate histone pre-mRNA processing in vivo. Comparisons with other mammalian ZFP100 orthologs show that the central Zn fingers sufficient for in vivo activity are most highly conserved, whereas the number and sequence of the $\mathrm{Zn}$ fingers in the $\mathrm{N}$ - and $\mathrm{C}$-terminal domains vary.
\end{abstract}

Keywords: histone mRNA; SLBP; cell cycle; Cajal body

\section{INTRODUCTION}

The cell-cycle regulation of histone expression is largely mediated by the unique $3^{\prime}$ terminus of the metazoan replication-dependent histone mRNAs (Stauber et al. 1986; Marzluff and Duronio 2002). These mRNAs end in a conserved stem-loop (SL) structure, rather than in a canonical polyadenylated tail (see Fig. 1). This $3^{\prime}$ end is formed by endonucleolytic cleavage of the nascent histone pre-mRNA between the SL and a second cis-acting sequence called the histone downstream element (HDE) (Gick et al. 1986; Mowry and Steitz 1987). Proper 3' end formation is crucial for multiple downstream steps in histone mRNA metabolism, including both its translation (Gallie et al. 1996;

Reprint requests to: William F. Marzluff, Program in Molecular Biology and Biotechnology, CB \#7100, University of North Carolina, Chapel Hill, NC 27599, USA; e-mail: marzluff@med.unc.edu; fax: (919) 962-1274.

Article published online ahead of print. Article and publication date are at http://www.rnajournal.org/cgi/doi/10.1261/rna.2606.
Sanchez and Marzluff 2002) and subsequent degradation (Pandey and Marzluff 1987; Kaygun and Marzluff 2005).

The SL is recognized and bound by a factor known as the stem-loop binding protein (SLBP) (Wang et al. 1996), also called the hairpin binding protein (HBP) (Martin et al. 1997). The HDE is a purine-rich sequence that interacts with the U7 snRNP by base-pairing with the $5^{\prime}$ end of U7 snRNA and is required for histone pre-mRNA processing (Schaufele et al. 1986; Cotten et al. 1988; Bond et al. 1991). The U7 snRNP is present at very low levels (500-1000 molecules/HeLa cell compared with $5 \times 10^{5}-$ $10^{6}$ molecules/cell for spliceosomal snRNPs), contains a noncanonical Sm binding site (Grimm et al. 1993) and is only known to function in processing of histone pre-mRNAs (Marzluff 2005). The U7 snRNP contains five Sm proteins common to other UsnRNPs; however, in lieu of Sm D1 and D2, it contains two Sm-like proteins, Lsm10 and Lsm11 (Pillai et al. 2001, 2003). This novel Sm-complex is responsible for recognizing the unusual Sm-site in U7 snRNA. U7 snRNA and Lsm10 both localize to Cajal bodies (CBs), which are found near the histone gene loci and may 
A

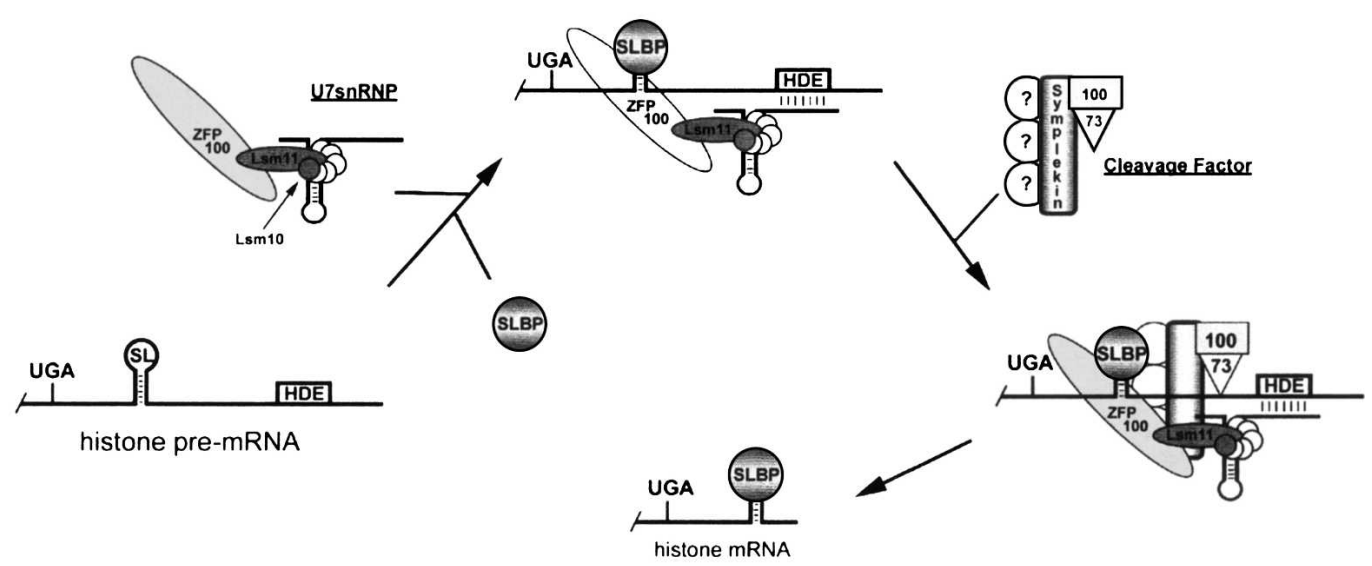

B



FIGURE 1. Histone pre-mRNA processing. (A) The two cis elements required for processing in the histone pre-mRNA are the stem-loop (SL) and the histone downstream element (HDE), which are bound by the SL Binding Protein (SLBP) and U7 snRNP, respectively. The three unique components of the U7 snRNP, Lsm10, Lsm11, and ZFP100, are shown. A cleavage factor containing symplekin (Kolev and Steitz 2005) and CPSF-73 is then recruited to catalyze the cleavage (Dominski et al. 2005). (B) Schematic of the protein structure of human ZFP100. Smaller numbers denote amino acid locations, large numbers within the protein denote each of the 18 zinc finger domains, and the N-terminal KRAB domain and region involved in SLBP/SL interaction are also labeled.

be the site of histone pre-mRNA processing in the nucleus (Frey and Matera 1995a; Pillai et al. 2001).

We previously cloned ZFP100, a novel 100-kDa Zn finger protein containing $18 \mathrm{C}_{2} \mathrm{H}_{2} \mathrm{Zn}$ fingers (Dominski et al. 2002), using a modified yeast-two hybrid assay to detect proteins that bind the SLBP/SL complex. Antibodies to ZFP100 precipitate U7 snRNA from nuclear extracts. Injection of ZFP100 cDNA into Xenopus oocytes stimulated processing of a reporter histone message, suggesting a positive role for this protein in histone pre-mRNA processing (Dominski et al. 2002).

Consistent with its role as a stable component of the active U7 snRNP, we report here that ZFP100 is a stable component of CBs using inverse fluorescence recovery after photobleaching (iFRAP) analysis. Furthermore, we found that $\mathrm{Zn}$ fingers 2-6 are necessary and sufficient for $\mathrm{CB}$ localization. We also found that $\mathrm{Zn}$ fingers 5-10 mediate its interaction with the Lsm11 protein of the U7snRNP. We define a 20-amino-acid region within Lsm11 that mediates its interaction with ZFP100. This region is conserved in vertebrates but absent in Drosophila, and the Drosophila Lsm11 protein does not interact with ZFP100. We developed a destabilized GFP reporter minigene containing a histone SL and HDE at the $3^{\prime}$ end as an assay for histone mRNA expression in cells. Expression of ZFP100 stimulates expression of the reporter. By using this assay, we find that the central $\mathrm{Zn}$ fingers 2-10 (amino acids 232-614) of
ZFP100 involved in CB localization, Lsm11 binding, and SLBP/SL interaction are also required and sufficient for activity. Zn fingers $11-18$ or the N-terminal 232 amino acids, including the KRAB domain, are not required for activity. Identification of four other mammalian ZFP100 genes show that only the central set of $\mathrm{Zn}$ fingers (amino acids 377-537) are well conserved, while the first 369 amino acids and last eight $\mathrm{Zn}$ fingers are not.

\section{RESULTS}

Our current view of histone pre-mRNA processing in mammalian cells is shown in Figure 1A. Two factors-SLBP, which binds the SL, and U7 snRNP, which binds to the HDE-recognize the histone pre-mRNA to initiate histone pre-mRNA processing. The large $\mathrm{Zn}$ finger protein, ZFP100, which interacts with both the U7 snRNP as well as the SLBP/histone pre-mRNA complex (Dominski et al. 2002), is important for stable recruitment of the U7 snRNP to the histone pre-mRNA. ZFP100 binds directly to the U7 snRNP-specific protein, Lsm 11 (Pillai et al. 2003; Azzouz et al. 2005). After the binding of SLBP and U7 snRNP, a cleavage factor that includes CPSF-73 (Dominski et al. 2005) and symplekin, as well as other proteins involved in polyadenylation (Kolev and Steitz 2005), associates with the complex. Although the mechanism of this interaction has not yet been defined, symplekin has been identified by 
Kolev and Steitz (2005) as the long-sought heat labile factor (Gick et al. 1987) and likely serves as a scaffold upon which to assemble the rest of the cleavage factor complex (Kolev and Steitz 2005). Since CPSF-73 crosslinks to the cleavage site (Dominski et al. 2005) and contains the motifs expected for an active $\mathrm{Zn}$-dependent endonuclease (Aravind 1999), it is likely the nuclease that endonucleolytically cleaves the pre-mRNA and then exonucleolytically degrades the downstream cleavage product (Dominski et al. 2005). By use of similar approaches, CPSF-73 has also been implicated as the endonuclease involved in cleavage of pre-mRNAs that are subsequently polyadenylated (Ryan et al. 2004).

ZFP100 is a limiting factor for histone pre-mRNA processing in HeLa cells (E.J.W. and W.F.M., in prep.). ZFP100 contains $18 \mathrm{Zn}$ fingers located in the C-terminal half of the protein, and a KRAB domain near the $\mathrm{N}$ terminus (Fig. 1B). We previously identified that $\mathrm{Zn}$ fingers 2-8 were required to mediate its interaction to the SLBP/SL complex (Dominski et al. 2002), but no other discrete domains or biological functions have been identified.

\section{ZFP100 is stably associated with Cajal bodies}

U7 snRNA is known to be concentrated in CBs, which are often localized adjacent to the replication-dependent histone gene clusters (Frey and Matera 1995a). To determine the localization of ZFP100, we fused full-length ZFP100 to the $\mathrm{N}$ terminus of the EGFP ORF and transfected very low levels of plasmid DNA (100 ng maximum per single $1-\mathrm{cm}$ well of a six-well plate) into HeLa cells. We found that the fusion protein localized to discrete foci in the nucleus along with a diffuse staining of the nucleoplasm (Fig. 2A).

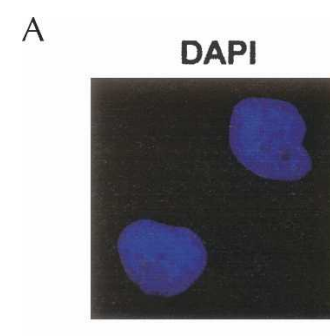

B

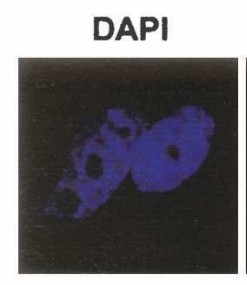

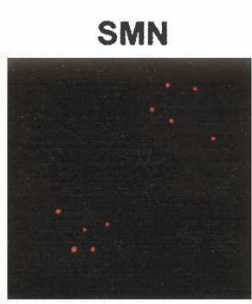

GFP-ZFP
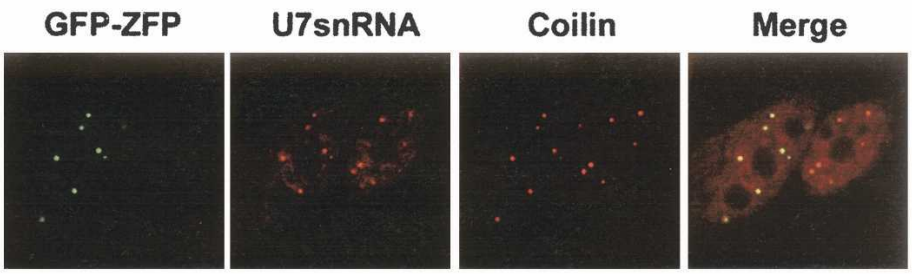

C

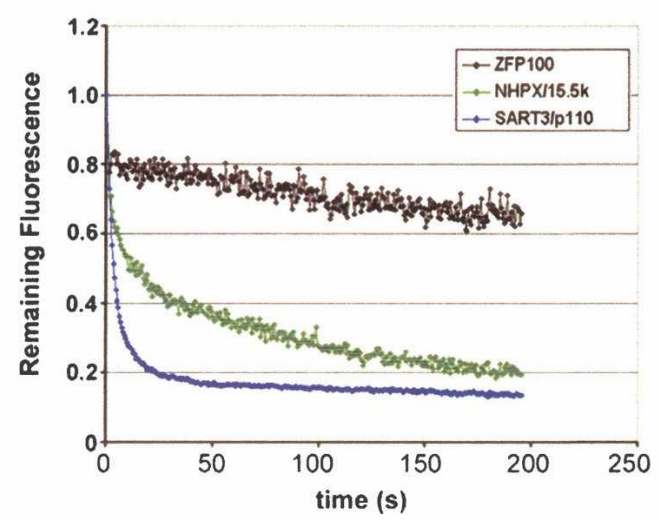

FIGURE 2. ZFP100 is a stable component of Cajal bodies. (A) HeLa cells were transfected with a ZFP100-GFP fusion protein and subject to indirect immunofluorescence by confocal microscopy to detect GFP, or antibodies against endogenous SMN (red) or coilin (yellow) to mark Cajal bodies. Cells were counterstained with DAPI to distinguish the nucleus (left), and the merged images are shown on the right. (B) HeLa cells were transfected with ZFP100-GFP fusion protein and incubated with a fluorescently labeled antisense oligonucleotide to U7 snRNA, coilin antibody, or the GFP was visualized directly. DNA was visualized by DAPI. The merged image is shown in the far right panel. ( $C$ ) Inverse-Frap (iFRAP) analysis of HeLa cells transfected with a ZFP100-GFP fusion protein. The $Y$-axis represents a percentage of the remaining fluorescence from a single Cajal body, and the $X$-axis reports the time throughout the experiment. The analyses of p110 and p15.5 have been reported previously (Dundr et al. 2004) and were done as internal controls. The ZFP100-GFP plot is an average of multiple experiments. 
Costaining with antibodies against the Survival of Motor Neurons protein (SMN) as well as with antibodies against coilin revealed that the ZFP100 foci were indeed CBs (Fig. 2A). Not surprisingly, in situ hybridization targeting U7 snRNA in cells transfected with the ZFP100GFP fusion protein also demonstrated 100\% coincident localization (Fig. 2B).

The discrete CB localization of ZFP100-GFP was observed only when low concentrations of DNA were transfected into HeLa cells, and optimal results were obtained with $100 \mathrm{ng} /$ well of a six-well plate. High levels of plasmid (>500 ng per/well) resulted in aberrant staining that included large and misshapen foci, many smaller diffuse foci, or in some cases cytoplasmic staining (data not shown). This observation suggests that the ZFP100 binding sites in the $\mathrm{CB}$ are present in low abundance and can be saturated. We have clearly overexpressed ZFP100-GFP substantially, since the fusion protein was readily detected on Western blots of whole-cell lysates using the antiZFP100 antibody, whereas the endogenous protein was not present at high enough concentrations to be detected. Thus it is likely that there are more binding sites in CBs for ZFP100 than there are molecules of ZFP100.

Among the many possible functions of $\mathrm{CBs}$ is the idea that they are sites for controlling histone mRNA biosynthesis, including sites of histone pre-mRNA processing (Marzluff 2005). Many of the components of CBs are transiently associated with the $\mathrm{CB}$, including the spliceosomal snRNPs and snoRNPs, which undergo maturation steps that involve passage through the CB (Jady et al. 2003). In contrast, U7 snRNP is quantitatively associated with CBs in Xenopus oocytes (Abbott et al. 1999). To determine whether the ZFP100 is stably associated with the CB, we used iFRAP to measure the residence times of ZFP100-GFP along with two other previously studied $\mathrm{CB}$ components, NHPX and SART3 (Dundr et al. 2004). Compared with the control proteins, ZFP100 was quite stably associated with CBs (Fig. 2C), whereas the other components were more transiently associated. The CB residence time of ZFP100 was similar to that of coilin (Dundr et al. 2004). These results strongly suggest that ZFP100 is stably associated with $\mathrm{CBs}$ and, more importantly, suggests that it may be a stable component of the U7 snRNP. Alternatively, ZFP100 could be targeted to CBs independently of U7 and transiently associate with the U7 snRNP within the CB.

\section{Zn fingers 2-6 of ZFP100 are necessary to maintain Cajal body localization}

We constructed a series of ZFP100 deletion mutants, which were either fused to EGFP or expressed as myc-tagged proteins, to determine which regions of ZFP100 were necessary for $\mathrm{CB}$ localization (Fig. 3A). Identical results were observed with either ZFP100-GFP or myc-ZFP100 proteins (data not shown). These mutant fusion proteins were transiently transfected into HeLa cells. Cells were fixed and counterstained for both endogenous coilin as well as DAPI to visualize nuclei. Sequential deletion of the 12 C-terminal $\mathrm{Zn}$ fingers had no effect on localization (data not shown). The ZFP100 mutant (ZF1-8), which has Zn fingers 9-18 deleted, formed discrete foci that were in most cases coincident with coilin (Fig. 3B, yellow arrows). However, some of these foci were not always precisely colocalized with coilin (blue arrows). In these instances, ZFP100 foci were typically adjacent to a $\mathrm{CB}$, and the identity and nature of these foci are unknown. Further deletion of $\mathrm{Zn}$ fingers 7 and 8 (ZF1-6) also resulted in CB staining with a few foci localizing adjacent to a $\mathrm{CB}$, demonstrating that the $\mathrm{N}$ terminus of ZFP, including just the first six Zn fingers, was sufficient to direct $\mathrm{CB}$ localization. In contrast, deletion of Zn fingers 5-18 (ZF1-4) resulted in diffuse nuclear staining in all cells with only a very subtle enrichment in $\mathrm{CB}$ intensity in a fraction of cells. ZF1-2, which contains only the $\mathrm{N}$ terminus through $\mathrm{Zn}$ fingers 1 and 2, exhibited uniform localization in the nucleus and the cytoplasm. It should be noted that although 16 of the $18 \mathrm{Zn}$ fingers have been deleted, the ZF1-2 mutant contains nearly the entire N-terminal half of ZFP100 (amino acids 1-342 out of 871). These experiments demonstrate that the N-terminal KRAB domain and the first four $\mathrm{Zn}$ fingers are not sufficient to mediate $\mathrm{CB}$ localization, while a protein containing the $\mathrm{N}$-terminal KRAB domain and the first six $\mathrm{Zn}$ fingers is appropriately localized.

Removal of the N-terminal KRAB domain and first $\mathrm{Zn}$ finger (ZF2-18) did not prevent localization to $\mathrm{CB}$, although in some cells, the overexpressed ZF2-18 protein was also localized to nucleoli (data not shown). Deletion of the $\mathrm{N}$ terminus through the first six $\mathrm{Zn}$ fingers resulted in diffuse nuclear staining with very little CB staining and with enrichment of ZF7-18 in the nucleoli. Further deletion from the N terminus to remove $\mathrm{Zn}$ fingers 1-8 (ZF9-18) resulted in a diffuse localization throughout the nucleus. The results with these deletions are consistent with the C-terminal deletions; we conclude that amino acids 322-481, including $\mathrm{Zn}$ fingers 2-6, are necessary to appropriately localize ZFP100 to CB.

We also expressed a series of proteins containing the first 210 amino acids (up to the first $\mathrm{Zn}$ finger) followed by six $\mathrm{Zn}$ fingers. The ZF13-18 and the ZF7-12 protein were nuclear. However, neither of these proteins was concentrated in CBs, consistent with the critical role for $\mathrm{Zn}$ fingers 2-6. The ZF5-10 protein was also nuclear and showed some concentration in CBs (yellow arrows, bottom panel). Thus, $\mathrm{Zn}$ fingers 5-6 alone have some ability to direct the ZF5-10 protein to CBs. To definitively demonstrate the role of Zn fingers 2-6 are necessary, we expressed two additional proteins: one containing only $\mathrm{Zn}$ fingers $2-6$, ZF2-6, and the other full-length ZFP100 lacking only Zn fingers $2-6$, ZF $\Delta 2-6$. The ZF2-6 protein localized to $C B$ and also was present in foci that were not coincident with $\mathrm{CB}$. The ZF $\Delta$ 2-6 protein localized diffusely throughout 


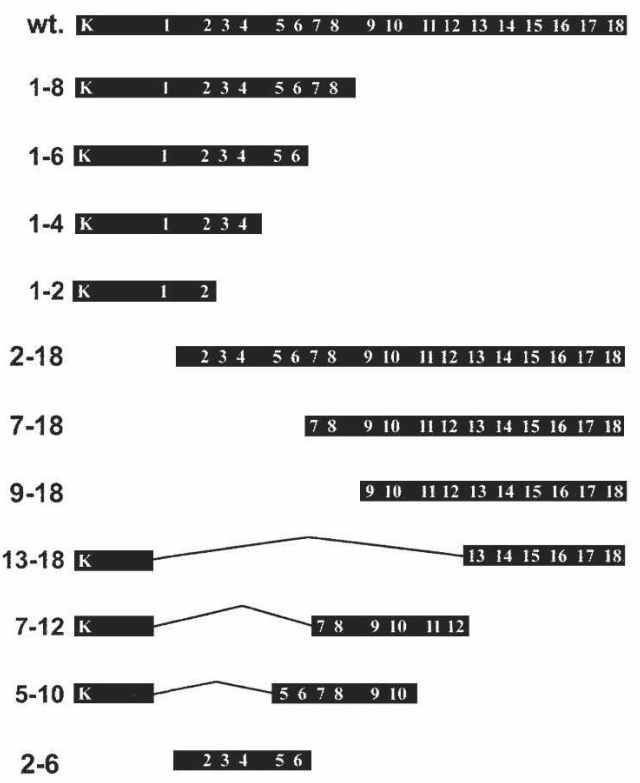

$\triangle 2-6 \mathrm{~K} \quad \mathrm{P} \longrightarrow 78 \quad 910 \quad 1112 \quad 13 \quad 14 \quad 15 \quad 16 \quad 17 \quad 18$
B

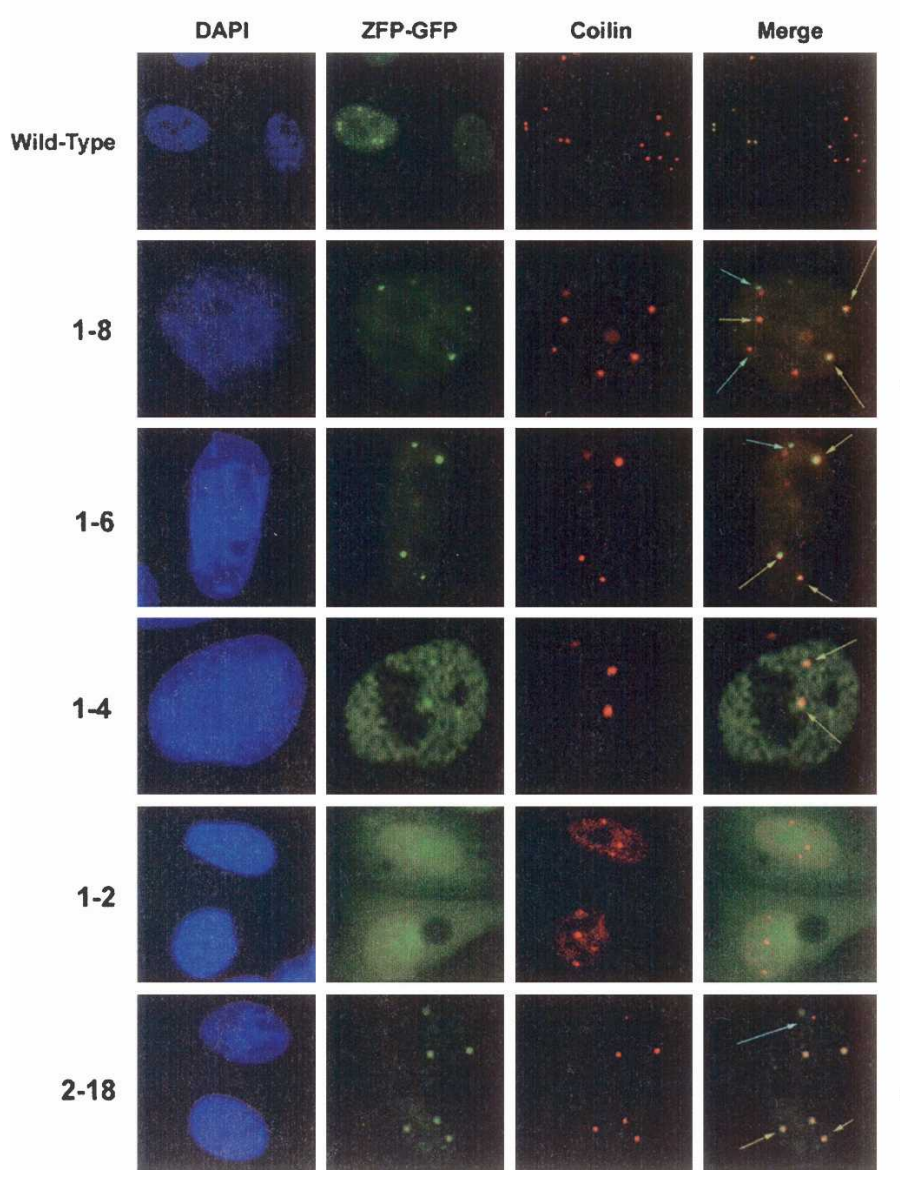

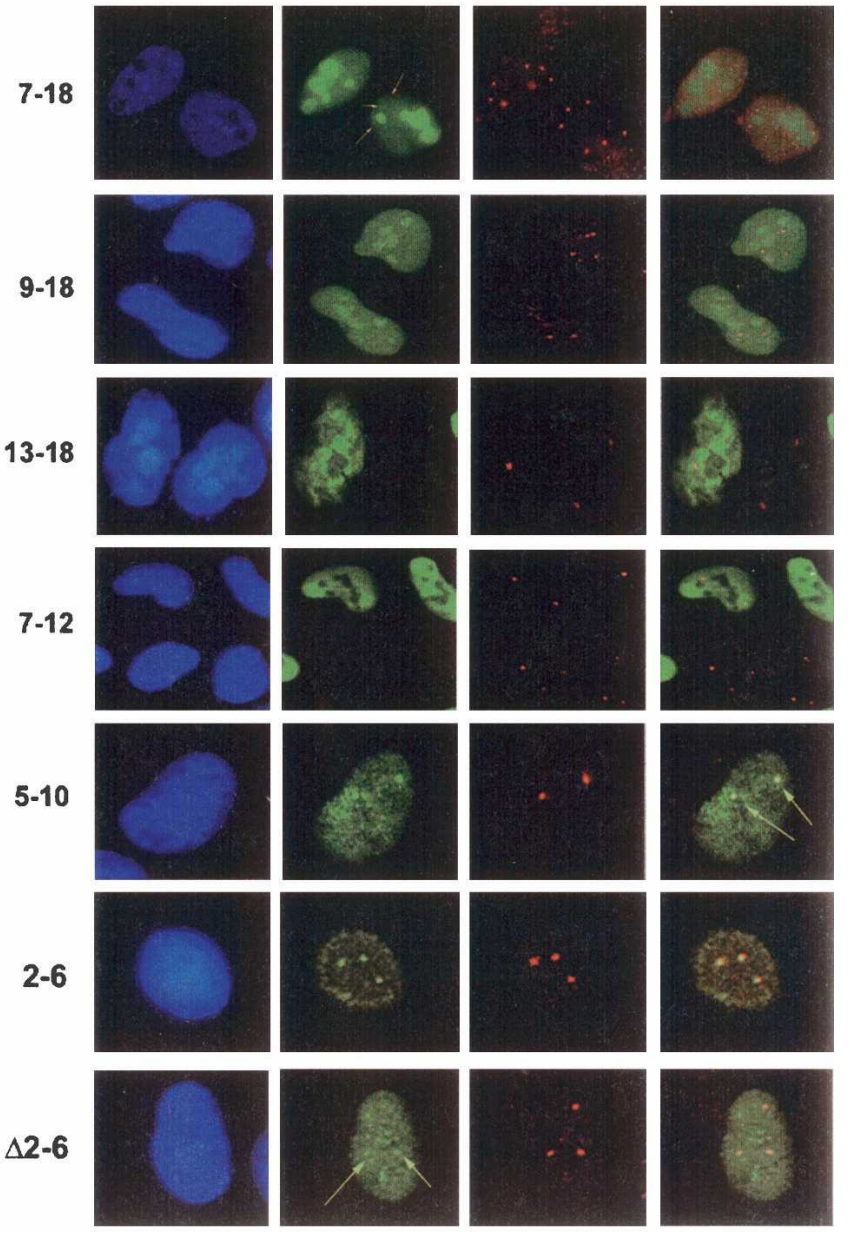

FIGURE 3. Mapping of regions of ZFP100 required for localization to Cajal bodies. $(A)$ Diagram of the ZFP constructs analyzed for Cajal body localization. The $\mathrm{K}$ indicates the KRAB domain, and the numbers represent the $18 \mathrm{Zn}$ fingers. $(B)$ Cells were transfected with the plasmids encoding the indicated ZFP protein, and $24 \mathrm{~h}$ later were analyzed by fluorescence microscopy. The images are of cells stained with DAPI to define the nuclei, a FITC filter to visualize either ZFP100-GFP fusion or myc-tagged ZFP100 proteins stained with anti-myc-FITC antibodies, and counterstained for endogenous coilin (red) by indirect immunofluorescence. Merged images are on the right side. The yellow arrows point to $100 \%$ coincident overlap between ZFP100 and coilin, and blue arrows point to adjacent coilin and ZFP100 staining. 
the nucleus, similar to the ZF7-18 construct. Taken collectively, these data demonstrate that $\mathrm{Zn}$ fingers 2-6 are necessary and sufficient for discrete CB localization.

\section{ZFP100 interacts with Lsm11 through Zn fingers 5-10}

The U7 snRNP-specific Sm protein, Lsm11, interacts directly with ZFP100 (Pillai et al. 2003; Azzouz et al. 2005). We determined the sites on ZFP100 and Lsm11 required for this interaction. To detect the binding of ZFP100 with Lsm11, full-length ZFP100 was translated in vitro in the presence of ${ }^{35} \mathrm{~S}$-methionine. Incubation of the labeled protein with an N-terminal fragment of recombinant GSTLsm11 protein (amino acids 1-100, lacking the C-terminal 260 amino acids, which includes both Sm domains) followed by pull-down with glutathione agarose and washing with a buffer containing $0.1 \%$ NP-40 and $0.54 \mathrm{M}$ $\mathrm{Na}^{+}$resulted in substantial pull-down of the ZFP100 protein. Reproducibly $50 \%$ of the input protein was pulled down under these conditions.

We used a series of deletions, similar to those used to map $\mathrm{CB}$ localization, to map the region of ZFP100 required to mediate its interaction with Lsm11. Deletions from the $\mathrm{N}$ terminus showed that removed the first 397 amino acids, including the first four $\mathrm{Zn}$ fingers had no effect on binding Lsm11, while removing the first $10 \mathrm{Zn}$ fingers caused a marked reduction in the binding to Lsm11, and further deletion abolished binding to Lsm11 (Fig. 4A). A series of C-terminal deletions showed that deletion of $\mathrm{Zn}$ fingers 1118 had no discernible effect on the binding with Lsm11. Further deletion of $\mathrm{Zn}$ fingers 9 and 10 resulted in a slight decrease in binding. However, further deletion of $\mathrm{Zn}$ fingers 5-8, leaving a protein containing only the first four $\mathrm{Zn}$ fingers, led to a dramatic loss of binding to Lsm11 (Fig. 4B).

These two sets of deletions demonstrate that the first 397 amino acids, including $\mathrm{Zn}$ fingers $1-4$, and amino acids 648-871 containing the C-terminal $\mathrm{Zn}$ fingers $11-18$ are not required for binding to Lsm11. Thus, these deletions suggest that the internal core of $\mathrm{Zn}$ fingers 5-10 is required for specific binding to Lsm11. Since the binding site for Lsm 11 is a series of $\mathrm{Zn}$ fingers, we sought to demonstrate that binding was specific to a particular set of $\mathrm{Zn}$ fingers. To address this question, we made a series of constructs that contained the first 210 amino acids (up to, but not including, $\mathrm{Zn}$ finger 1) followed by six $\mathrm{Zn}$ fingers, $\mathrm{Zn}$ fingers $1-6,7-12$, and $13-18$ and tested their ability to bind to Lsm11. The protein containing $\mathrm{Zn}$ fingers $1-6$ bound Lsm11, although not as well as full-length ZFP100, while there was essentially no binding to the proteins containing Zn fingers $7-12$ or $13-18$ (Fig. 4C). This result demonstrates that it is not simply the number of $\mathrm{Zn}$ fingers that determine binding; there is also an underlying specificity to the interaction. To further define the requirements for binding, we constructed additional clones containing $\mathrm{Zn}$ fingers 4-8, 5-10, and 5-12. The protein containing $\mathrm{Zn}$ fingers 5-10 or 5-12 bound Lsm11 as well as the full-length protein, whereas $\mathrm{Zn}$ fingers $4-8$ and 7-12 did not bind Lsm11. To definitively demonstrate the role of ZF5-10 in Lsm11 binding, we constructed ZF5-10, containing only Zn fingers 5-10 without the $\mathrm{N}$ terminal region, and this protein bound as well as the full-length protein. In contrast, $\mathrm{ZF} \Delta 5-10$, which contains $12 \mathrm{Zn}$ fingers and the entire rest of the protein, showed only weak binding. These results clearly demonstrate that $\mathrm{Zn}$ fingers 5-10 are necessary and sufficient for binding to Lsm11, whereas Zn fingers 1-6 are necessary and sufficient to localize ZFP100 to CBs. Thus the regions required for these two properties of ZFP100 partially overlap.

\section{Interaction of human Lsm11 with ZFP100 requires a 20-amino-acid domain present in vertebrate Lsm11}

In their initial identification of Lsm11, Schümperli and coworkers demonstrated that the N-terminal 136 amino acids of Lsm11 are sufficient to mediate its interaction with ZFP100 (Pillai et al. 2003). In a more recent study, they demonstrated that several clustered point mutations within the highly conserved regions of the $\mathrm{N}$ terminus of Lsm11 did not affect binding to ZFP100; thus a discrete domain within Lsm11 that specifically binds ZFP100 has not yet been identified (Azzouz et al. 2005).

We generated a Clustal-W alignment of the first 100 amino acids of Lsm11 from several species, including two invertebrates and three vertebrates (Fig. 5A). There are two major regions of high conservation (shown with brackets) that have been reported to be important for Lsm11 function (Azzouz et al. 2005). There is also a region that is invariant in vertebrates (shown with stars) but that is only weakly conserved in two invertebrates. Finally, there is an arginine-glycine-rich region present between amino acids 60-80 that is present in vertebrates but absent from both the Drosophila and Ciona Lsm11.

We created a series of recombinant GST-Lsm 11 fusion proteins that deleted 20-amino-acid blocks from Lsm11 (Fig. 5A). These mutants were expressed in Escherichia coli, purified, and analyzed by gel electrophoresis to quantify the amount of full-length protein (Fig. 5B, upper panel). Some of the proteins were partially cleaved in E. coli, leaving a fragment slightly longer than GST in addition to the fulllength fragment (Fig. 5B, lanes 2,6,7,13,14). These Lsm11 proteins were incubated with ${ }^{35}$ S-labeled ZFP100 synthesized in a rabbit reticulocyte lysate, and the complexes were pulled down using glutathione agarose beads. Deletion of the first 20, 40, or 60 amino acids of Lsm11 had no effect on its ability to bind to ZFP100 (Fig. 5B, lanes 2-4). However, when amino acids 1-60 were incubated with ZFP100, there was no binding (Fig. 5B, lane 6). Furthermore, amino acids $60-100$ of Lsm 11 bound ZFP100 as well as amino acids $1-100$ (Fig. 5B, lanes 7,8). The first 60 amino acids contain the two most highly conserved regions 
A

wt.

$5-18$

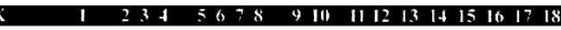

11-18

56.78 9 III III I2 13 IA 151617 18

112131415161718

$15-18$

IE 161718

B

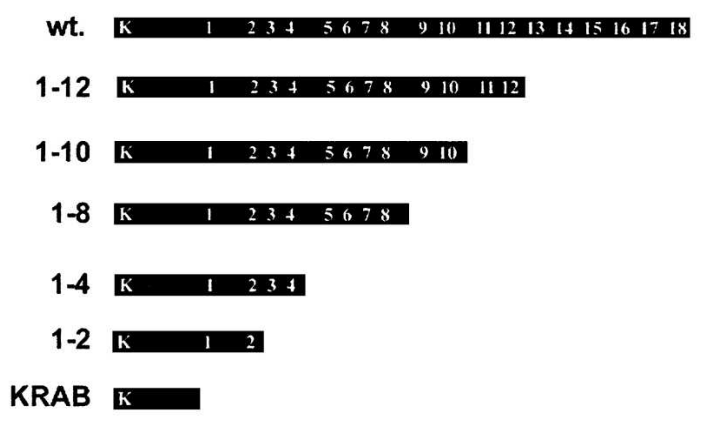

C

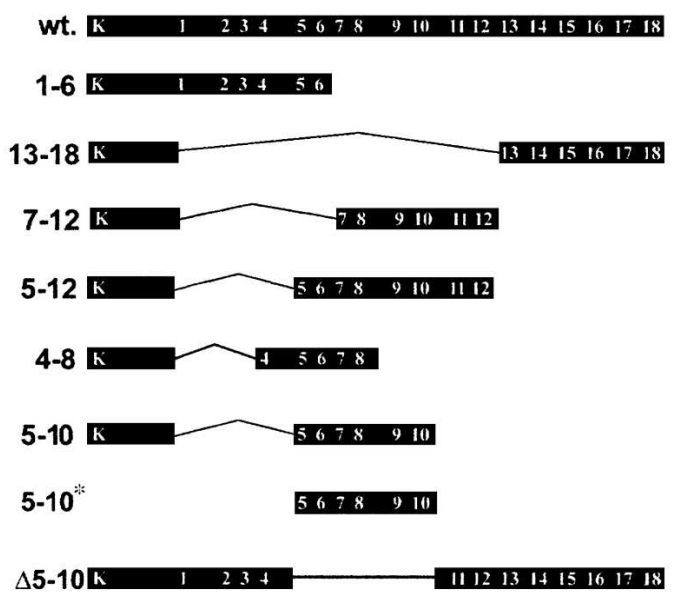

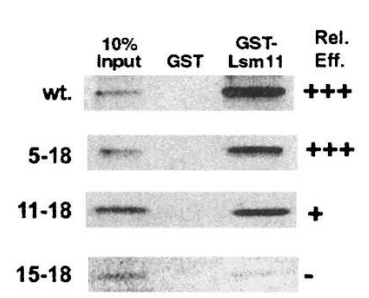
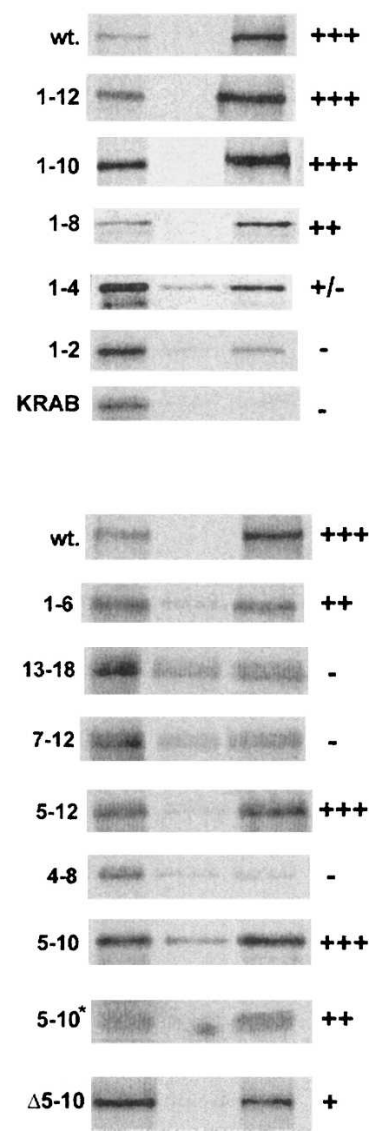

FIGURE 4. Region of ZFP100 that interacts with Lsm11. (A) On the left is a schematic of a series of deletions of ZFP100 from the N terminus. On the right are the GST pull-down experiments. The ZFP100 proteins were labeled with ${ }^{35}$ S-methionine by translation of synthetic mRNA in a reticulocyte lysates. The lysates were then incubated with either GST or a GST-Lsm 11 fusion protein containing the first 100 residues of Lsm11. Ten percent of the input (left lanes) was analyzed together with the protein bound to GST (center lanes) or the GST-Lsm11 (right lanes) The extent of binding of the mutants is indicated by the following scale represented by the pluses and minuses:,$+++>80 \%$ pulled down relative to full-length ZFP100; ,$++>60 \% ;+,>40 \%$; \pm , between $2 \%$ and $40 \%$; and,$-<2 \%$ of wild-type. All experiments are representative of at least three independent experiments. $(B)$ On the left is a schematic of a series of deletions from the $\mathrm{C}$ terminus, and on the right are the GST pull-down experiments. The experiments and scaling are identical as described for panel $A$. (C) On the left is a schematic of a series of zinc fingers fused to the N-terminal region of ZFP100, and on the right are GST pull-down experiments. The experiments and scaling are identical as in panel $A$.

of Lsm11, and surprisingly, these regions are not involved in binding ZFP100. Inspection of the residues within amino acids $60-100$ shows a stretch of arginines and glycines that are present in the vertebrate Lsm11 proteins but absent in Drosophila and Ciona Lsm11. A GST protein containing only amino acids 63-82 (Fig. 5B, lane 11), which contains the arginine and glycine rich region, was capable of pulling down as much ZFP100 as a fragment containing amino acids $60-100$ (Fig. 5B, lane 10 vs. 11), demonstrating that this discrete region within vertebrate Lsm11 is sufficient to mediate its interaction with ZFP100. This arginine-glycine-rich region is conspicuously absent in the Drosophila Lsm11 N-terminal region, and consistent with this lack of conservation; the first 100 amino acids of the Drosophila Lsm11 (dm1-100) did not bind human ZFP100 (Fig. 5B, lane 13).

\section{Stimulation of histone pre-mRNA processing in vivo by ZFP100 requires the central conserved core of zinc fingers}

We constructed a GFP-SL reporter gene encoding a destabilized GFP driven by a histone gene promoter and ending in the histone $3^{\prime}$ end processing signal to allow visualization of reporter histone mRNAs (Fig. 6A), using as a control a GFP reporter ending in a polyA tail (E.J. Wagner and W.F. Marzluff, in prep.). Expression of ZFP100 in cells stimulates expression of the GFP-SL gene in a concentration-dependent manner (Fig. 6B). We determined the $3^{\prime}$ end of the mRNAs expressed from this gene in the presence of increasing amounts of ZP100. In the absence of exogenous ZFP100, very little processed mRNA was formed, but there are some read-through RNA transcripts formed (Fig. 6B, lane 1, arrowheads). Expression of increasing amounts of ZFP100 resulted in an increase in properly processed GFP-SL mRNA (Fig. 6B, lanes 2-4) and GFP activity measured by fluorescence. We used this assay to determine which regions of ZFP100 were required for this stimulation, focusing on the $\mathrm{Zn}$ finger regions identified as necessary for CB localization and Lsm11 binding. We transfected a number of $\mathrm{Zn}$ finger mutants (Fig. 6C) with a myc-tag at the $\mathrm{N}$ terminus and detected the proteins by Western blotting. All of these proteins were expressed to similar levels as determined by Western blotting detecting the myc tag (Fig. 6D), except for 
A



B



FIGURE 5. Amino acids 63-82 of Lsm11 are necessary and sufficient for binding ZFP100. (A) Clustal-W-generated alignment of the first 100 amino acids of Lsm11 from several species. Shaded regions represent conserved amino acids. The two bracketed regions are highly conserved and are required for Lsm11 function (Azzouz et al. 2005). The $*$ region is conserved only in vertebrates. Below the alignment are schematics of the GST-Lsm11 fusion proteins used for pull-down of ZFP100. (B) The results of a GST pull-down assay using the various GST-Lsm11 fusion proteins and ${ }^{35}$ S-labeled ZFP100. The various GST-Lsm11 deletion mutants used in each pull-down were analyzed by gel electrophoresis and stained with Coomassie blue. An image of the gel is shown above each assay. For some proteins there was proteolysis of a portion of the Lsm11 protein of the GST-fusion, but in each case the top band corresponds to the full-length fusion protein. In lane 13 a GST fusion with the first 100 amino acids of Drosophila Lsm 11 was analyzed. The bottom panel shows the amount of ${ }^{35}$ S-ZFP100 pulled down by each GST-Lsm11 protein. In all cases, the same amount of full-length ZFP100 was used, and the results presented are representative of multiple experiments.

the ZF2-18, which has the $\mathrm{N}$ terminus deleted and was expressed at low levels. We have generally observed that any protein lacking the KRAB domain accumulates to low levels in cells.

We cotransfected these myc-tagged ZFP100 deletion mutants with the H2A-SL reporter (Fig. 6B) and either assayed fluorescence by using FACS analysis (Fig. 6E, upper graph) or analyzed the increase in reporter mRNA by Northern blotting (Fig. 6E, lower). The ZFP protein containing $\mathrm{Zn}$ fingers 1-12 was as active as the full-length protein, while proteins containing only the first 210 amino acids (KRAB) or Zn fingers 11-18 showed little activity (Fig. 6D). Taking into account the low expression of ZF218 , this protein was as active as the wild-type protein. The protein containing $\mathrm{Zn}$ fingers 1-10 also had close to full-length activity, again taking into account the lower expression level of this protein. Proteins containing $\mathrm{Zn}$ fingers, $1-6,5-12$, and 5-10 had lower activity, and these proteins are deficient either in CB localization (5-12 and 5-10) or in Lsm11 binding (1-6). Note that in this in vivo assay, ZFP100 is overexpressed relative to the endogenous $\mathrm{ZFP}$, and since multiple $\mathrm{Zn}$ fingers show nonspecific binding to Lsm11 under some conditions (Azzouz et al. 2005), it is not surprising that these results do not precisely mirror the results obtained with Lsm11 binding in vitro or with CB localization. Clearly, however, Zn fingers 5-6 and 9-10 both contribute to specific interaction with Lsm11 (Fig. 4), and this likely accounts for the relatively high activity of the protein containing Zn fingers 9-18 relative to 11-18, and for the activity of the $1-6,4-8$, and 7-12 protein in this assay, each of which contains either $\mathrm{Zn}$ fingers 5 and 6 or 9 and 10 .

Collectively, these data suggest that the internal core $\mathrm{Zn}$ fingers $2-10$ are critical for all the known functions of ZFP100: binding Lsm11 (Zn fingers 5-10), localization to CBs (Zn fingers 2-6), activity in histone pre-mRNA processing ( $\mathrm{Zn}$ fingers $2-10$ ), and binding to SLBP ( $\mathrm{Zn}$ fingers 2-8) (Dominski et al. 2002). Furthermore, $\mathrm{Zn}$ fingers $11-18$ or the first 210 amino acids of ZPF100 are not required for any of these functions. 
A

\section{B}


FIGURE 6. The conserved core of ZFP100 stimulates expression of the GFP-SL reporter in cells. (A) A diagram of the GFP-SL reporter construct. (B) Results of S1 protection assay of RNA isolated from cells transfected with either the GFP-SL reporter and either lacZ (lane 1), as a control, or increasing amounts of myc-ZFP100 (lanes 2-4). The undigested probe is labeled at the left of the gel, while the pre-mRNA/readthrough and properly cleaved GFP mRNA are labeled on the right. In addition to the processed mRNA (arrow) and some undigested probe, there are a series of heterogenous bands (arrowheads) that likely reflect read-through transcripts. The graph on the right shows relative GFP units from the GFP-SL and GFP-polyA plasmids, vs. increasing amounts of myc-ZFP100 plasmid. Results were obtained by using FACS analysis and are representative of three independent transfections. $(C)$ A schematic of the deletion mutants of ZFP100, all of which contained a myc tag at the N terminus. $(D)$ Cells were transfected with plasmids encoding the indicated ZFP100 mutant and the GFP-SL reporter construct, $20 \mathrm{~h}$ after transfection cells were harvested, lysates prepared and analyzed by Western blotting with anti-myc to detect the ZFP100 mutants (top), and then reprobed with antiSLBP (bottom). In the first lane, the cells were transfected with myc-tagged lacZ as a control. (E) Transfected cells were also used to measure the fluorescence for each of the ZFP100 mutants. The results are reported as the amount of arbitrary fluorescence units above those in the cells transfected with LacZ. Below the graph is a Northern blot of the GFP-SL RNA and an ethidium bromide stained gel of the ribosomal RNA from each sample.

\section{Conservation of ZFP100}

We used a bioinformatic approach to identify ZFP100 genes from other species and to identify areas of conservation. It was only possible to identify orthologs of ZFP100 in mammalian genomes, due to the abundance of proteins that contain $\mathrm{C} 2 \mathrm{H} 2 \mathrm{Zn}$ fingers and the relatively rapid evolution of ZFP100. We were not able to identify orthologs from other vertebrate genomes (chicken, zebrafish, or Xenopus). We relied on synteny and the diagnostic gene structure of ZFP100 to identify putative orthologs. The ZFP100 gene contains only five exons, with the
C-terminal exon containing $>91 \%$ of the protein sequence. Human ZFP100 is located on chromosome 19 in the q13.33 band. This genomic locus is syntenic with a portion of mouse chromosome 7, rat chromosome 1, chimpanzee chromosome 20, and dog chromosome 1. All of the candidate ZFP100 genes are located within these regions of their respective genomes.

The major marker used to confirm the synteny was the vaccinia-related kinase 3 gene (vrk3) (Nichols and Traktman 2004), which is a readily identifiable gene in the Ensembl database and is located adjacent to the human ZFP100 
gene. In each of the other species, the obvious ortholog of the human vrk3 gene is also located adjacent to the candidate ZFP100 gene within this syntenic locus. As a further proof that the identified orthologs of human ZFP100 are indeed correct, the pre-mRNA structures for all of the ZFP100 genes are similar. These mRNAs are the result of splicing of either four or five exons where the 3' exon is $>2 \mathrm{~kb}$ and contains all of the $\mathrm{Zn}$ fingers, while the first exons are much smaller. This combination of syntenic genomic location and similar pre-mRNA organization allowed us to conclude that these are true orthologs of human ZFP100.

Alignment of the ZFP100 amino acid sequences revealed a strong conservation within the central core $\mathrm{Zn}$ fingers 4-8 and a surprising degree of dissimilarity at both the $\mathrm{N}$ and $\mathrm{C}$ termini (Fig. 7). Between the closely related human and chimpanzee ZFP100 genes, Zn fingers 14 and 15 in human ZFP100 are missing from the chimpanzee gene and from the ZFP100 genes from the other species. In contrast, Zn fingers $16-18$ are clearly present in the other species, except the dog, where $\mathrm{Zn}$ finger 18 is not present. There are also differences between the mouse and rat genes with a new $\mathrm{Zn}$ finger between $\mathrm{Zn}$ fingers 12 and 13 in the mouse. In the most conserved core region $\mathrm{Zn}$ fingers 4-8, there is another $\mathrm{Zn}$ finger between 4 and 5 in mouse, rat, and dog, and there is a "pseudofinger" in this position in human and chimpanzee. In the dog ZFP100 gene, there are two $\mathrm{Zn}$ fingers inserted between fingers 8 and 11, making a total of four fingers in this region. Surprisingly $\mathrm{Zn}$ fingers 9 and 10 , required for maximal Lsm11 binding in our assays, are missing from the mouse and rat ZFP100. Perhaps the presence of the $\mathrm{Zn}$ finger between fingers 4 and 5 compensates for the loss for $\mathrm{Zn}$ fingers 9 and 10 in these species.

In the $\mathrm{N}$ terminus of ZFP100, there are also clear differences among the genes. Each gene contains three $\mathrm{Zn}$ fingers prior to the conserved $\mathrm{Zn}$ finger 4, but in the mouse and rat, there is a new Zn finger between finger 1 and 2, with finger 3 now a pseudo $\mathrm{Zn}$ finger. In human and chimpanzee, there is a pseudo $\mathrm{Zn}$ finger between fingers 1 and 2, while in the dog, $\mathrm{Zn}$ finger 1 is missing. Overall, the region containing $\mathrm{Zn}$ fingers $4-8$ (amino acids 377-537) is the most conserved, with $47 \%$ identity, while the first 210 amino acids show 20\% identity and amino acids 211-369 containing fingers $1-3$ show $35 \%$ identity. This result is consistent with the functional results reported here that this region is necessary for the known biological functions of ZFP100.

\section{DISCUSSION}

Histone mRNA biosynthesis requires only a single processing step, endonucleolytic cleavage, to form the mature $3^{\prime}$ end of histone mRNA. This unique $3^{\prime}$ end is present only on metazoan replication-dependent histone mRNAs, the only nonpolyadenylated mRNAs in eukaryotes. It plays an important role not only in the metabolism of histone mRNA but also in the coordinate regulation of the multiple histone mRNAs expressed in mammalian cells. A critical factor in histone mRNA metabolism and regulation is SLBP, which interacts with the SL at the $3^{\prime}$ end of histone mRNA. One function of SLBP is to help recruit the U7 snRNP to the HDE in the histone pre-mRNA (Dominski et al. 1999). ZFP100 was identified as a protein that interacts with the SLBP bound to the SL RNA, and this interaction requires the region of SLBP required for histone pre-mRNA processing (Dominski et al. 2002). Antibodies to the ZFP100 precipitated some U7 snRNA from nuclear extracts, suggesting that ZFP100 is a component of the U7 snRNP. U7 snRNP purified by affinity chromatography, using a biotinylated antisense oligonucleotide complementary to the $5^{\prime}$ end of U7 snRNA, contained only proteins that migrated at $<50 \mathrm{kDa}$ (Smith et al. 1991; Pillai et al. 2001) and hence did not contain ZFP100, raising the

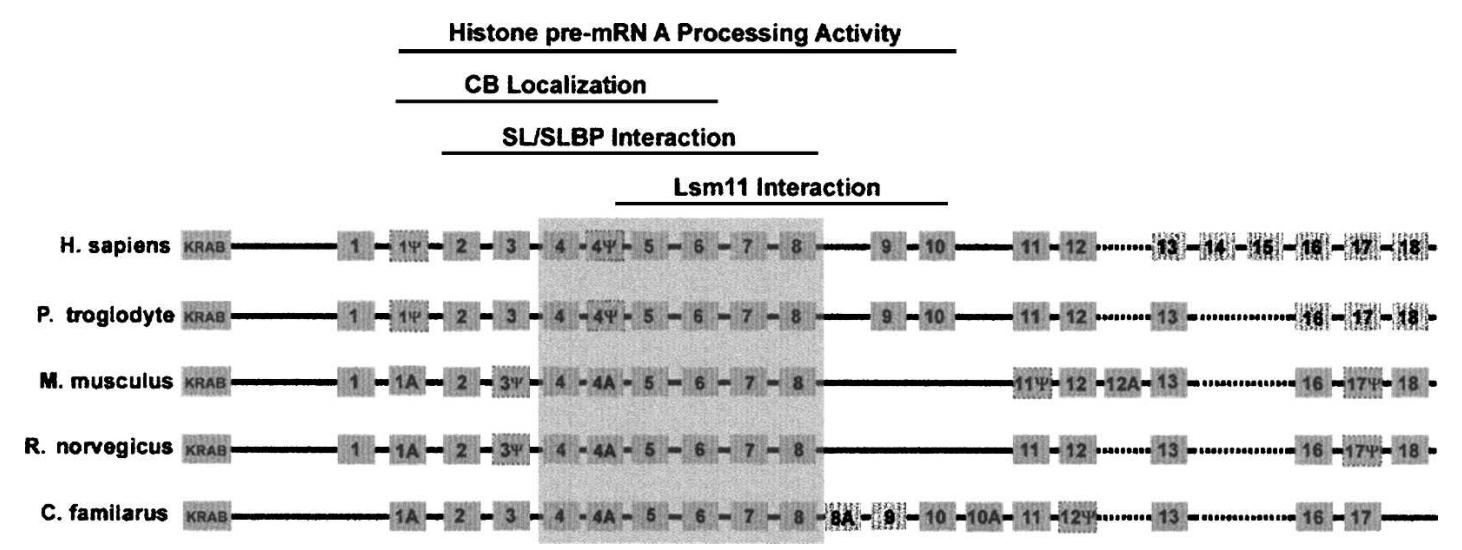

FIGURE 7. Comparison of mammalian ZFP100 protein sequences. The Zn fingers in human ZFP100 are indicated as 1-18. Clear "pseudo" Z fingers (with one of the conserved $\mathrm{C} 2 \mathrm{H} 2$ residues mutated) are indicated with a $\Psi$. Additional $\mathrm{Zn}$ fingers are indicated with an A. Deletions are indicated by dotted lines. 
possibility that ZFP100 is not tightly associated with the core U7 snRNP or that it is present substoichiometrically. We recently showed that ZFP100 is a limiting factor for histone pre-mRNA processing in mammalian cells (E.). Wagner and W.F. Marzluff, in prep.).

In vertebrate cells, U7 snRNP is highly concentrated in CBs (Wu and Gall 1993; Frey and Matera 1995b; Abbott et al. 1999). The mechanisms responsible for targeting and maintaining U7 snRNP in CBs are not known. Our finding that ZFP100 is a stable component of CBs is consistent with it also being a stable component of U7 snRNP. Targeting ZFP100 to CBs requires a subset of the $\mathrm{Zn}$ fingers, and these do not completely overlap with the $\mathrm{Zn}$ fingers required for high-affinity binding to Lsm11. Since ZFP100 is concentrated in CBs even when ZFP100 is overexpressed, it is possible that ZFP100 may localize to the CBs independently from U7 snRNP and not simply as a result of its interaction with Lsm11. It is possible that binding of ZFP100 to Lsm11 is responsible for the retention of U7 snRNP in CBs.

\section{Zn fingers 2-10 are sufficient for the biochemical functions of ZFP100}

There are four biochemical properties of ZFP that have been described: (1) it binds the SL/SLBP complex (Dominski et al. 2002); (2) it binds to Lsm11 (Pillai et al. 2003); (3) it is localized to CBs (this work); and (4) expression of ZFP100 stimulates expression of the H2A-SL reporter (E.J. Wagner and W.F. Marzluff, in prep.). All four of these activities require only a subset of the $\mathrm{Zn}$ fingers in $\mathrm{ZFP} 100, \mathrm{Zn}$ fingers 2-10. The regions of ZFP100 required for each individual activity are not completely overlapping. In particular, $\mathrm{Zn}$ fingers 2-6 are sufficient for localization to CBs but do not bind Lsm11 strongly, while Zn fingers 5-10 bind Lsm11 as well as full-length ZFP100 but do not concentrate in CBs. Interaction with the SLBP/RNA complex in the histone pre-mRNA requires $\mathrm{Zn}$ fingers 2-8, extending further N-terminal to the region required for binding Lsm11 (Dominski et al. 2002). We did not find a requirement for any other regions of ZFP100 for any of these ZFP functions, although the N-terminal KRAB domain clearly helps stabilize the overexpressed ZFP100. Thus it is likely that when ZFP100 binds to the SLBP/RNA complex, the $\mathrm{Zn}$ fingers 2-10, Lsm11, and SLBP are localized together close to the cleavage site. Following assembly of the U7 snRNP on the pre-mRNA, this complex likely participates in the recruitment of a complex containing symplekin and CPSF73 to the cleavage site (Dominski et al. 2005; Kolev and Steitz 2005).

\section{ZFP100 interacts specifically with a small region of vertebrate Lsm11}

Recently Azzouz and coworkers (2005) also studied the interaction of ZFP100 with Lsm11. They suggested that the interaction of ZFP100 with the $\mathrm{N}$ terminus of Lsm11 was due to a nonspecific interaction with a number of $\mathrm{Zn}$ fingers. Their experiments were performed under relatively low stringency conditions (washes in PBS, $140 \mathrm{mM} \mathrm{NA}^{+}$, compared with $540 \mathrm{mM} \mathrm{NA}^{+}$that was used in this study), and we observed significant nonspecific binding when we used these wash conditions. We compared the binding of four different fragments of ZFP100 each containing six Zn fingers. Clearly the fragment containing $\mathrm{Zn}$ fingers 5-10 bound efficiently and the fragment containing $\mathrm{Zn}$ fingers 1-6 bound less well, while $\mathrm{Zn}$ fingers $7-12$ or $13-18$ were not active in binding (Fig. 5). These results, coupled with the finding that a specific set of $\mathrm{Zn}$ fingers was essential for localization to CBs and was the only region that stimulated histone pre-mRNA processing, strongly support the idea that the specific interaction of $\mathrm{Zn}$ fingers 5-10 with the $\mathrm{N}$-terminal region of Lsm11 is important for the function of U7 snRNP. The high conservation in this region among the mammalian orthologs of ZFP100 further supports the idea that this region is critical to ZFP100 function. Exactly how it functions in histone pre-mRNA processing and cell cycle regulation remains to be determined.

We have also identified the region of Lsm11 responsible for binding ZFP100. The binding activity can be localized to a 20-amino-acid region, which has been conserved in vertebrates but not invertebrate Lsm11. This region of Lsm11 was not explicitly tested in the experiments of Azzouz et al. (2005), who focused on only conserved regions within the $\mathrm{N}$ terminus. The ZFP100 binding site is conserved only in vertebrate Lsm11, consistent with our observation that human ZFP100 does not interact with Drosophila Lsm11 and that dSLBP and hSLBP are not interchangeable in histone pre-mRNA processing in vitro (Dominski et al. 2002). It is likely that the highly conserved region close to the $\mathrm{N}$ terminus of Lsm11 interacts with other factors required for histone pre-mRNA processing, and together with ZFP100, this region certainly could be involved in recruiting the cleavage factor.

\section{MATERIALS AND METHODS}

\section{Plasmid construction}

The plasmids expressing ZFP100 were constructed in pEGFP-N1 (Clontech) with a GFP protein fused to the $\mathrm{C}$ terminus. The GFP-SL reporter clone was constructed by cloning the H2A-614 promoter in place of the CMV promoter of the pEGFPd4-N1 plasmid (Clontech) and replacing the SV40 polyA site with the H2A-614 SL and HDE. Myc-tagged ZFP clones were made by insertion of PCR-generated ZFP fragments cloned into the KpnI and ApaI sites of pcDNA4-TO-HisB. pXFRM clones were generated by insertion of PCR-generated ZFP fragments and cloned into the BamHI and XbaI sites. The GST fusion clones expressing fragments of Lsm11 were constructed in pGEX with the fragments of Lsm11 fused to the C terminus of GST. All clones were sequenced, and all primers are available upon request. 


\section{Cell culture and transfection}

Hek 293T and HeLa cells were cultured by using standard techniques with DMEM low-glucose medium supplemented with $10 \%$ fetal bovine serum. Cells were transfected with plasmids by using either Lipofectamine or Lipofectamine 2000 according to manufacturer's protocols (Invitrogen).

\section{Immunoblotting}

293T cells transfected with myc-tagged ZFP100 were harvested by incubation with hot SDS loading buffer followed by five passes through a 22-gauge needle. Lysates were resolved by SDS-PAGE and blotted with anti-myc monoclonal antibody (Invitrogen) at a dilution of 1:1000. Blots were probed with a 1:1000 dilution of polyclonal antiserum raised against SLBP.

\section{FACS analysis}

For analysis of GFP fluorescence, 293T cells were harvested by using trypsin and then added to $37 \%$ formaldehyde to achieve a final concentration of $0.5 \%$. Cell fluorescence was quantified by using a FACscan machine, and the data were analyzed by using Summit.

\section{Localization}

Cells were grown on chamber slides (Nunc) to $50 \%-80 \%$ confluence. Transfections utilized SuperFect Transfection Reagent (Qiagen) and were conducted as per the manufacturer's instructions. Cells were fixed in $4 \%$ paraformaldehyde for $10 \mathrm{~min}$ and then permeabilized in ice-cold $0.5 \%$ Triton X-100 for $5 \mathrm{~min}$. Immunofluorescence was performed by using anti-SMN ( $\mathrm{mAb}$ at 1:200 Transduction Laboratories) and anti-coilin rabbit serum (R124 at 1:600). Secondary antibodies, anti-rabbit Texas red, and anti-mouse Cy5 (1:200) were obtained from Vector Laboratories and Amersham Pharmacia, respectively.

\section{iFRAP analysis}

The analysis was carried out essentially as previously described (Dundr et al. 2004). HeLa cells were grown in DMEM (Invitrogen) supplemented with 10\% FCS (Invitrogen), 1\% glutamine, and penicillin and streptomycin at $37^{\circ} \mathrm{C}$ in $5 \% \mathrm{CO}_{2}$. The cells were electroporated with a BTX electroporator ECM 830 using $5 \mu \mathrm{g}$ plasmid DNA and $15 \mu \mathrm{g}$ sheared salmon sperm carrier DNA in a 2 -mm gap cuvette at $200 \mathrm{~V}, 1$ msec pulse, 4 pulses, and 0.5 -sec intervals. After electroporation the cells were plated in Nalgene Lab Tek II chambers, and after $\sim 6 \mathrm{~h}$, the medium was changed to DMEM with $25 \mathrm{mM}$ Hepes without phenol red (Invitrogen). iFRAP experiments were performed on Zeiss 510 confocal microscope with a $100 \times / 1.3$ N.A. planapochromat oil objective. GFP was excited with the 488-nm line of Argon laser, and GFP emission was monitored above $505 \mathrm{~nm}$ as described (Dundr et al. 2004). Cells were maintained at $37^{\circ} \mathrm{C}$ with a Nevtek ASI 400 Air Stream incubator (Nevtek). The whole nuclear area of transfected cells was bleached except a small region of one $\mathrm{CB}$ using the 488 -nm laser line at $100 \%$ laser power. Cells were monitored in $0.5-\mathrm{sec}$ intervals for $195 \mathrm{sec}$. For quantification, the loss of total fluorescent intensity in the unbleached region of interest was measured by using Zeiss software. Background fluorescence was measured in a random field outside of the cells. For each time point, the relative loss of fluorescent intensity in the unbleached region of interest was calculated as:

$\mathrm{I}_{\text {rel }}=\left(\mathrm{I}_{(\mathrm{t})}-\mathrm{BG}\right) /\left(\mathrm{I}_{\mathrm{o}}-\mathrm{BG}\right) \times\left(\mathrm{T}_{(\mathrm{t})}-\mathrm{BG}\right)$, where $\mathrm{I}_{\mathrm{o}}$ is the background-corrected average intensity of the region of interest during prebleach and $\mathrm{T}_{(\mathrm{t})}$ is the background-corrected total fluorescence intensity of a neighboring control cell.

\section{In vitro binding experiments}

Various deletion mutants of ZFP100 were cloned into the pXFRM plasmid (Wang et al. 1999), which produces a polyadenylated mRNA after transcription with T7 RNA polymerase. Binding experiments were performed by incubating $5 \mu \mathrm{L}$ of reticulocyte lysate containing the translated ZFP100 with recombinant GST protein or recombinant GST-Lsm11 using the conditions described (Erkmann et al. 2005). Following the incubation, the beads were washed with PBS supplemented with $0.1 \%$ NP-40 and 400 $\mathrm{mM} \mathrm{NaCl}$ (final $\mathrm{Na}^{+}$concentration of $540 \mathrm{mM}$ ) to reduce nonspecific binding. Beads were then mixed with $2 \times$ SDS loading buffer and resolved by using PAGE. Quantification of the ${ }^{35} \mathrm{~S}$-methionine signal was performed by using a phosphorimager (Molecular Dynamics) followed by analysis using ImageQuant software.

\section{ACKNOWLEDGMENTS}

We thank Bob Duronio (UNC) for many helpful discussions and critical comments on the manuscript. This work was supported by grants from the NIH to W.F.M. (R01 GM 29832), E.J.W. (F32 GM070101-02 and T32-CA09156), J.K.O. (T32 GM08613), and A.G.M. (RO1 GM 53034 and RO1 NS41617). E.J.W. also acknowledges support from the Cottrell Foundation.

Received January 4, 2006; accepted March 29, 2006.

\section{REFERENCES}

Abbott, J., Marzluff, W.F., and Gall, J.G. 1999. The stem loop binding protein (SLBP1) is present in coiled bodies of the Xenopus germinal vesicle. Mol. Biol. Cell 10: 487-499.

Aravind, L. 1999. An evolutionary classification of the metallo$\beta$-lactamase fold proteins. In Silico Biol. 1: 69-91.

Azzouz, T.N., Gruber, A., and Schümperli, D. 2005. U7 snRNPspecific Lsm11 protein: dual binding contacts with the $100 \mathrm{kDa}$ zinc finger processing factor (ZFP100) and a ZFP100-independent function in histone RNA 3' end processing. Nucleic Acids Res. 33: 2106-2117.

Bond, U.M., Yario, T.A., and Steitz, J.A. 1991. Multiple processingdefective mutations in a mammalian histone premessenger RNA are suppressed by compensatory changes in U7 RNA both in vivo and in vitro. Genes \& Dev. 5: 1709-1722.

Cotten, M., Gick, O., Vasserot, A., Schaffner, G., and Birnstiel, M.L. 1988. Specific contacts between mammalian U7 snRNA and histone precursor RNA are indispensable for the in vitro RNA processing reaction. EMBO J. 7: 801-808.

Dominski, Z., Zheng, L.-X., Sanchez, R., and Marzluff, W.F. 1999. The stem-loop binding protein facilitates $3^{\prime}$ end formation by stabilizing U7 snRNP binding to the histone pre-mRNA. Mol. Cell. Biol. 19: 3561-3570.

Dominski, Z., Erkmann, J.A., Yang, X., Sanchez, R., and Marzluff, W.F. 2002. A novel zinc finger protein is associated 
with U7 snRNP and interacts with the stem-loop binding protein in the histone pre-mRNP to stimulate $3^{\prime}$-end processing. Genes \& Dev. 16: $58-71$.

Dominski, Z., Yang, X.C., and Marzluff, W.F. 2005. The polyadenylation factor CPSF-73 is involved in histone pre-mRNA processing. Cell 123: 37-48.

Dundr, M., Hebert, M.D., Karpova, T.S., Stanek, D., Xu, H., Shpargel, K.B., Meier, U.T., Neugebauer, K.M., Matera, A.G., and Misteli, T. 2004. In vivo kinetics of Cajal body components. J. Cell Biol. 164: 831-842.

Erkmann, J.A., Wagner, E.J., Dong, J., Zhang, Y.P., Kutay, U., and Marzluff, W.F. 2005. Nuclear import of the stem-loop binding protein and localization during the cell cycle. Mol. Biol. Cell 16: 2960-2971.

Frey, M.R. and Matera, A.G. 1995a. Coiled bodies contain U7 small nuclear RNA and associate with specific DNA sequences in interphase human cells. Proc. Natl. Acad. Sci. 92: 59155919.

- 1995b. Coiled bodies contain U7 small nuclear RNA and associate with specific DNA sequences in interphase human cells. Proc. Natl. Acad. Sci. 92: 5915-5919.

Gallie, D.R., Lewis, N.J., and Marzluff, W.F. 1996. The histone 3'terminal stem-loop is necessary for translation in Chinese hamster ovary cells. Nucleic Acids Res. 24: 1954-1962.

Gick, O., Krämer, A., Keller, W., and Birnstiel, M.L. 1986. Generation of histone mRNA $3^{\prime}$ ends by endonucleolytic cleavage of the premRNA in a snRNP-dependent in vitro reaction. EMBO J. 5: 1319 1326.

Gick, O., Krämer, A., Vasserot, A., and Birnstiel, M.L. 1987. Heatlabile regulatory factor is required for $3^{\prime}$ processing of histone precursor mRNAs. Proc. Natl. Acad. Sci. 84: 8937-8940.

Grimm, C., Stefanovic, B., and Schümperli, D. 1993. The low abundance of U7 snRNA is partly determined by its Sm binding site. EMBO J. 12: 1229-1238.

Jady, B.E., Darzacq, X., Tucker, K.E., Matera, A.G., Bertrand, E., and Kiss, T. 2003. Modification of Sm small nuclear RNAs occurs in the nucleoplasmic Cajal body following import from the cytoplasm. EMBO J. 22: 1878-1888.

Kaygun, H. and Marzluff, W.F. 2005. Regulated degradation of replication-dependent histone mRNAs requires both ATR and Upf1. Nat. Struct. Mol. Biol. 12: 794-800.

Kolev, N.G. and Steitz, J.A. 2005. Symplekin and multiple other polyadenylation factors participate in $3^{\prime}$-end maturation of histone mRNAs. Genes \& Dev. 19: 2583-2592.

Martin, F., Schaller, A., Eglite, S., Schümperli, D., and Müller, B. 1997. The gene for histone RNA hairpin binding protein is located on human chromosome 4 and encodes a novel type of RNA binding protein. EMBO J. 16: 769-778.

Marzluff, W.F. 2005. Metazoan replication dependent histone mRNAs: A unique class of RNA polymerase II transcripts. Curr. Opin. Cell Biol. 17: 274-280.
Marzluff, W.F. and Duronio, R.J. 2002. Histone mRNA expression: Multiple levels of cell cycle regulation and important developmental consequences. Curr. Opin. Cell Biol. 14: 692-699.

Mowry, K.L. and Steitz, J.A. 1987. Identification of the human U7 snRNP as one of several factors involved in the $3^{\prime}$ end maturation of histone premessenger RNA's. Science 238: 1682-1687.

Nichols, R.J. and Traktman, P. 2004. Characterization of three paralogous members of the Mammalian vaccinia related kinase family. J. Biol. Chem. 279: 7934-7946.

Pandey, N.B. and Marzluff, W.F. 1987. The stem-loop structure at the $3^{\prime}$ end of histone mRNA is necessary and sufficient for regulation of histone mRNA stability. Mol. Cell. Biol. 7: 4557-4559.

Pillai, R.S., Will, C.L., Lührmann, R., Schümperli, D., and Müller, B. 2001. Purified U7 snRNPs lack the Sm proteins D1 and D2 but contain Lsm10, a new $14 \mathrm{kDa}$ Sm D1-like protein. EMBO J. 20: $5470-5479$.

Pillai, R.S., Grimmler, M., Meister, G., Will, C.L., Luhrmann, R., Fischer, U., and Schümperli, D. 2003. Unique Sm core structure of U7 snRNPs: Assembly by a specialized SMN complex and the role of a new component, Lsm11, in histone RNA processing. Genes \& Dev. 17: 2321-2333.

Ryan, K., Calvo, O., and Manley, J.L. 2004. Evidence that polyadenylation factor CPSF-73 is the mRNA $3^{\prime}$ processing endonuclease. RNA 10: 565-573.

Sanchez, R. and Marzluff, W.F. 2002. The stem-loop binding protein is required for efficient translation of histone mRNA in vivo and in vitro. Mol. Cell. Biol. 22: 7093-7104.

Schaufele, F., Gilmartin, G.M., Bannwarth, W., and Birnstiel, M.L. 1986. Compensatory mutations suggest that base-pairing with a small nuclear RNA is required to form the $3^{\prime}$ end of $\mathrm{H} 3$ messenger RNA. Nature 323: 777-781.

Smith, H.O., Tabiti, K., Schaffner, G., Soldati, D., Albrecht, U., and Birnstiel, M.L. 1991. Two-step affinity purification of U7 small nuclear ribonucleoprotein particles using complementary biotinylated 2 ' $-O$ methyl oligoribonucleotides. Proc. Natl. Acad. Sci. 88: 9784-9788.

Stauber, C., Lüscher, B., Eckner, R., Lotscher, E., and Schümperli, D. 1986. A signal regulating mouse histone $\mathrm{H} 4 \mathrm{mRNA}$ levels in a mammalian cell cycle mutant and sequences controlling RNA $3^{\prime}$ processing are both contained within the same 80 -bp fragment. EMBO J. 5: 3297-3303.

Wang, Z.-F., Whitfield, M.L., Ingledue, T.I., Dominski, Z., and Marzluff, W.F. 1996. The protein which binds the $3^{\prime}$ end of histone mRNA: A novel RNA- binding protein required for histone pre-mRNA processing. Genes \& Dev. 10: 3028-3040.

Wang, Z.-F., Ingledue, T.C., Dominski, Z., Sanchez, R., and Marzluff, W.F. 1999. Two Xenopus proteins that bind the $3^{\prime}$ end of histone mRNA: Implications for translational control of histone synthesis during oogenesis. Mol. Cell. Biol. 19: 835-845.

Wu, C.-H.H. and Gall, J.G. 1993. U7 small nuclear RNA in C snurposomes of the Xenopus germinal vesicle. Proc. Natl. Acad. Sci. 90: 6257-6259. 

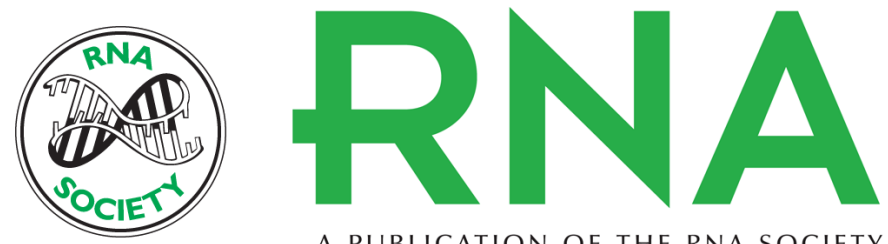

A PUBLICATION OF THE RNA SOCIETY

\section{Conserved zinc fingers mediate multiple functions of ZFP100, a U7snRNP associated protein}

Eric J. Wagner, Jason K. Ospina, Yue Hu, et al.

RNA 2006 12: 1206-1218

References This article cites 35 articles, 23 of which can be accessed free at:

http://rnajournal.cshlp.org/content/12/7/1206.full.html\#ref-list-1

\section{License}

Email Alerting Receive free email alerts when new articles cite this article - sign up in the box at the Service top right corner of the article or click here.

To subscribe to RNA go to:

http://rnajournal.cshlp.org/subscriptions 